\title{
Experimental strength evaluation of steel-polypropylene hybrid fibre reinforced concrete
}

DOI:10.36909/jer.ACMM.16345

\author{
A. Arokiaprakash ${ }^{*}$ and S. Senthil Selvan \\ Department of Civil Engineering, SRM Institute of Science and Technology, Kattankulathur- \\ 603203, TamilNadu, India. \\ *Corresponding author: arokiapa@srmist.edu.in
}

\begin{abstract}
Reinforced concrete structures collapse by developing tensile and flexural crack patterns. The properties of the concrete must be researched to prevent these forms of failure and enhance the overall strength and durability. The inclusion of fibres in the concrete increasing the strength of the concrete and prevents micro-cracks that lead to a major failure. In this study, two different types of fibres are considered for inclusion in the concrete as Hybrid fibre in which one has higher moduli (Steel fibre) and one has lesser moduli (Polypropylene fibre). This hybrid material formulation can reduce the probability of brittleness and micro-cracks forming in concrete. The mix design used for this investigation is M40 grade of concrete designed as per IS10262:2019. The hybrid combination of Steel and Polypropylene fibre ratio is 50:50 with different hybridization percentages as $1 \%, 1.5 \%$ and $2 \%$. The compression, splitting tensile and flexural tests were carried out to study the hybrid concrete behavior for the three different hybridization dosage percentages and the same were carried out for the controlled concrete. The experimental study revealed that the inclusion of the hybrid fibre increases the strength of the concrete
\end{abstract}


compared to the conventional concrete. The hybridization of $1.5 \%$ gives the higher strength results and it is considered as an optimum percentage.

Keywords: Hybridization; steel-fibre; polypropylene-fibre; mechanical properties; strength increment.

\section{INTRODUCTION}

Hybrid fiber-reinforced concrete is a high-strength construction material composed of two different types of short fibres (Bentur and Mindess, 1990). The hybridization of the discrete fibres in the concrete-mix is uniformly distributed and randomly oriented. Besides, HyFRC can be accompanied by typical reinforcement (steel bars), post-tensioning and prestressing concrete (Caggiano et al., 2016). When the elastic limit of the concrete under tension is exceeded, the formation of microcracks starts. Three-dimensional propagation of the fibres, suitable for withstanding the triaxial loads, can be achieved through hybridization (Qiana and Stroevenb, 2000). The inclusion of the fibre content improves post-peak response in flexural, which means increased capacity to carry the load (Hemapriya et al., 2019). It is used for rehabilitation of structural components and provides an improvement in ductility, durability, increased shear and crack resistance and it reduces the crack widths (Fangqian Denga et al., 2018; Banthia and Gupta, 2004). Non-structural components comprise the majority of HyFRC implementations.

This is largely due to a lack of code to direct the design of HyFRC components (Pliya et $a l .$, 2011). However, as FRC is used in non-structural applications, the behavior of the FRC can be analyzed and improved as well (Song et al., 2005; Singh et al., 2010). The earthquake-affected concrete structural members showed the significance of designing concrete members with ductile behavior. The tendency of reinforced concrete components to withstand massive amounts of 
energy emitted during earthquakes without losing strength under higher magnitude within the elastic limit is referred to as ductility (Santhakumar AR, 2005; Soon Poh Yap et al., 2014). It can be obtained by using hybridization usage of the fibres. In this study, the combination of Steel and polypropylene fibre included in the concrete as a hybrid with the proportion of 50:50 (Steel: Polypropylene) in different hybridization ratios such as $1 \%, 1.5 \%$ and $2 \%$. The compression, splitting tensile and flexural tests were carried out to analyze the hybrid concrete behavior of the different hybridization ratios.

\section{EXPERIMENTAL STUDY}

The preliminary experimental tests were carried out to determine the basic mechanical properties of the material.

\subsection{Cement}

The cement used for the study is OPC-53 grade as per IS 12269-1970. The properties of the material listed in Table 1.

Table 1. Cement-Physical Properties.

\begin{tabular}{|l|l|}
\hline Materials Properties & Value \\
\hline Cement & OPC 53 grade \\
\hline Specific-Gravity & 3.15 \\
\hline Soundness & $7.2 \mathrm{~mm}$ \\
\hline Normal consistency & $35 \%$ \\
\hline Initial setting time & $30 \mathrm{mins}$ \\
\hline Final setting time & $245 \mathrm{mins}$ \\
\hline
\end{tabular}




\subsection{Fine aggregate}

Manufactured sand (M-Sand) confirming Zone - III as per IS: 383-1970 is applied for this study. The properties of the material given in Table 2 .

Table 2. M-Sand-Physical Properties.

\begin{tabular}{|l|l|}
\hline Materials Properties & Value \\
\hline Fine Aggregate (M-Sand) & Zone III \\
\hline Specific-Gravity & 2.6 \\
\hline Fineness Modulus & 2.95 \\
\hline Water absorption & $0.5 \%$ \\
\hline
\end{tabular}

\subsection{Coarse aggregate}

The crushed granite type coarse aggregate of passing $12.5 \mathrm{~mm}$ and retaining on $10 \mathrm{~mm}$ sieve size angular in shape used for the experiments. The properties of the material given in Table 3.

Table 3. Physical Properties.

\begin{tabular}{|l|l|}
\hline Materials Properties & Value \\
\hline Coarse aggregate (size) & $12.5 \mathrm{~mm}$ \\
\hline Specific-Gravity & 2.79 \\
\hline Fineness Modulus & 5.25 \\
\hline Water Absorption (\%) & 1.70 \\
\hline
\end{tabular}




\subsection{Steel fibres}

The discrete steel fibres used in this study are the high tensile strength straight hooked end. The properties of the material given in Table 4.

Table 4. Steel fibre- hooked end.

\begin{tabular}{|l|l|}
\hline Materials Properties & Value \\
\hline Steel-fibre length & $50 \mathrm{~mm}$ \\
\hline Dia & $1 \mathrm{~mm}$ \\
\hline Aspect-ratio & 50 \\
\hline Specific-Gravity & 7.8 \\
\hline Tensile strength & $1250-1550 \mathrm{MPa}$ \\
\hline
\end{tabular}

\subsection{Polypropylene fibre}

The synthetic polypropylene fibre used in this study is highly resistant to acids, alkalies and displays good heat-insulating properties. The properties of the material given in Table 5.

Table 5. Polypropylene fibre- properties.

\begin{tabular}{|l|l|}
\hline Materials Properties & Value \\
\hline Polypropylene fibre length & $12 \mathrm{~mm}$ \\
\hline Dia & $0.04 \mathrm{~mm}$ \\
\hline Aspect-ratio & 300 \\
\hline Tensile strength & $300-400 \mathrm{MPa}$ \\
\hline
\end{tabular}

A Mix design of 1:2.07:2.14:0.5 proportion taken for this experimental study as presented in table 6 based on IS 10262:2019. The weight fractions of hybridization fibres of $1 \%, 1.5 \%$ and 
$2 \%$ are given in table 7 . The hybrid fibres were gradually added to the dry mix during the preparation of the concrete before the addition of water to ensure the fibres were spread evenly. The compression test specimens are of cube size $100 \mathrm{~mm}$ x $100 \mathrm{~mm}$ x $100 \mathrm{~mm}$, the splitting tensile test specimens are of cylinder size $100 \mathrm{~mm}$ x $200 \mathrm{~mm}$ and flexural tensile strength specimens are of prisms size $500 \mathrm{~mm}$ x $100 \mathrm{~mm}$ x $100 \mathrm{~mm}$ were cast. All the specimens were cured in the potable water inside the curing tank immediately remove from the mould after the basic setting time of 24 hours. The compression and splitting tensile strength test was scheduled for the $7^{\text {th }}$ day, $14^{\text {th }}$ day and $28^{\text {th }}$ day. The test samples were cured according to the testing schedule and surface dried for a minimum of 6 hours before testing. The experimental set-up and placing of the specimen for the test as shown in Figure 1. (a), (b) and (c).

Table 6. Weight of Mix proportions for $1 \mathrm{~m}^{3}$ of concrete.

\begin{tabular}{|c|c|c|c|c|c|c|}
\hline $\begin{array}{l}\text { Grade of } \\
\text { concrete }\end{array}$ & $\begin{array}{c}\text { Cement } \\
(\mathrm{Kg})\end{array}$ & $\begin{array}{c}\text { Water } \\
\text { (lt) }\end{array}$ & $\begin{array}{c}\text { Coarse } \\
\text { aggregate } \\
(\mathrm{Kg})\end{array}$ & $\begin{array}{c}\text { M-Sand } \\
\text { (Kg) }\end{array}$ & $\begin{array}{l}\text { Water- } \\
\text { cement } \\
\text { ratio }\end{array}$ & $\begin{array}{c}\text { Steel: polypropylene } \\
(50 \%: 50 \% \text { of the volume } \\
\text { of cement) }\end{array}$ \\
\hline M40 (Hybrid) & 416 & 208 & 894 & 868 & 0.5 & $1 \%, 1.5 \%$ and $2 \%$ \\
\hline
\end{tabular}

Table 7. Volume fractions of hybridization fibres.

\begin{tabular}{|c|c|c|c|c|c|}
\hline \multirow{2}{*}{$\begin{array}{l}\text { Percentage of } \\
\text { Hybridization of } \\
\text { fibre in concrete }\end{array}$} & \multicolumn{2}{|c|}{$\begin{array}{l}\text { Steel: polypropylene } \\
\qquad(\mathbf{5 0 : 5 0 )}\end{array}$} & \multirow{2}{*}{$\begin{array}{l}\text { Weight of } \\
\text { Steel fibre } \\
\mathrm{Kg} / \mathrm{m}^{3}\end{array}$} & \multirow{2}{*}{$\begin{array}{l}\text { Weight of } \\
\text { Polypropylene } \\
\text { fibre } \mathrm{Kg} / \mathrm{m}^{3}\end{array}$} & \multirow{2}{*}{$\begin{array}{l}\text { Total weight of } \\
\text { Fibre in } \\
\text { concrete } \mathrm{Kg} / \mathrm{m}^{3}\end{array}$} \\
\hline & Steel & Polypropylene & & & \\
\hline $1 \%$ & $0.5 \%$ & $0.5 \%$ & 39.45 & 4.55 & 44 \\
\hline $1.5 \%$ & $0.75 \%$ & $0.75 \%$ & 59.18 & 6.83 & 66.01 \\
\hline $2 \%$ & $1 \%$ & $1 \%$ & 78.9 & 9.1 & 88 \\
\hline
\end{tabular}




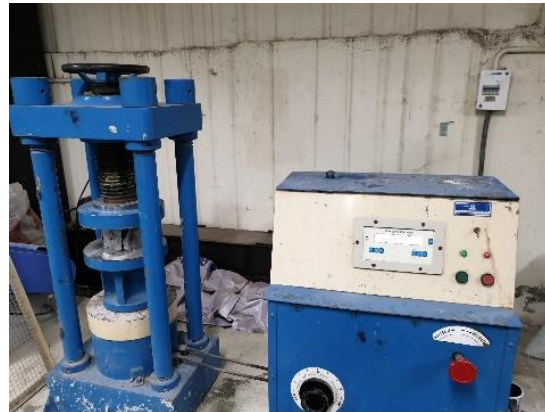

(a) Compression testing

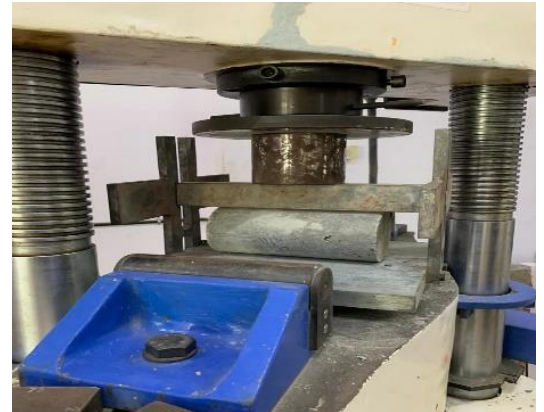

(b) Splitting tensile

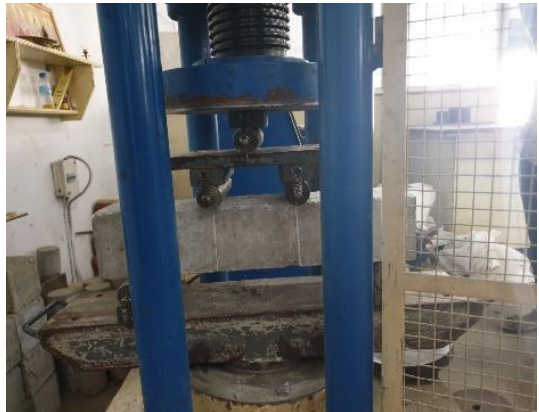

(c) Flexural

Figure. 1 Experimental set-up.

\section{RESULT INTERPRETATIONS}

\subsection{Effect of hybrid fibers on compressive strength}

The casted cubes of different hybridization percentages with different testing schedules tested in a compression testing machine conforming to the IS 516: 1959. The results were plotted in the graph and depicted in Figure. 2.
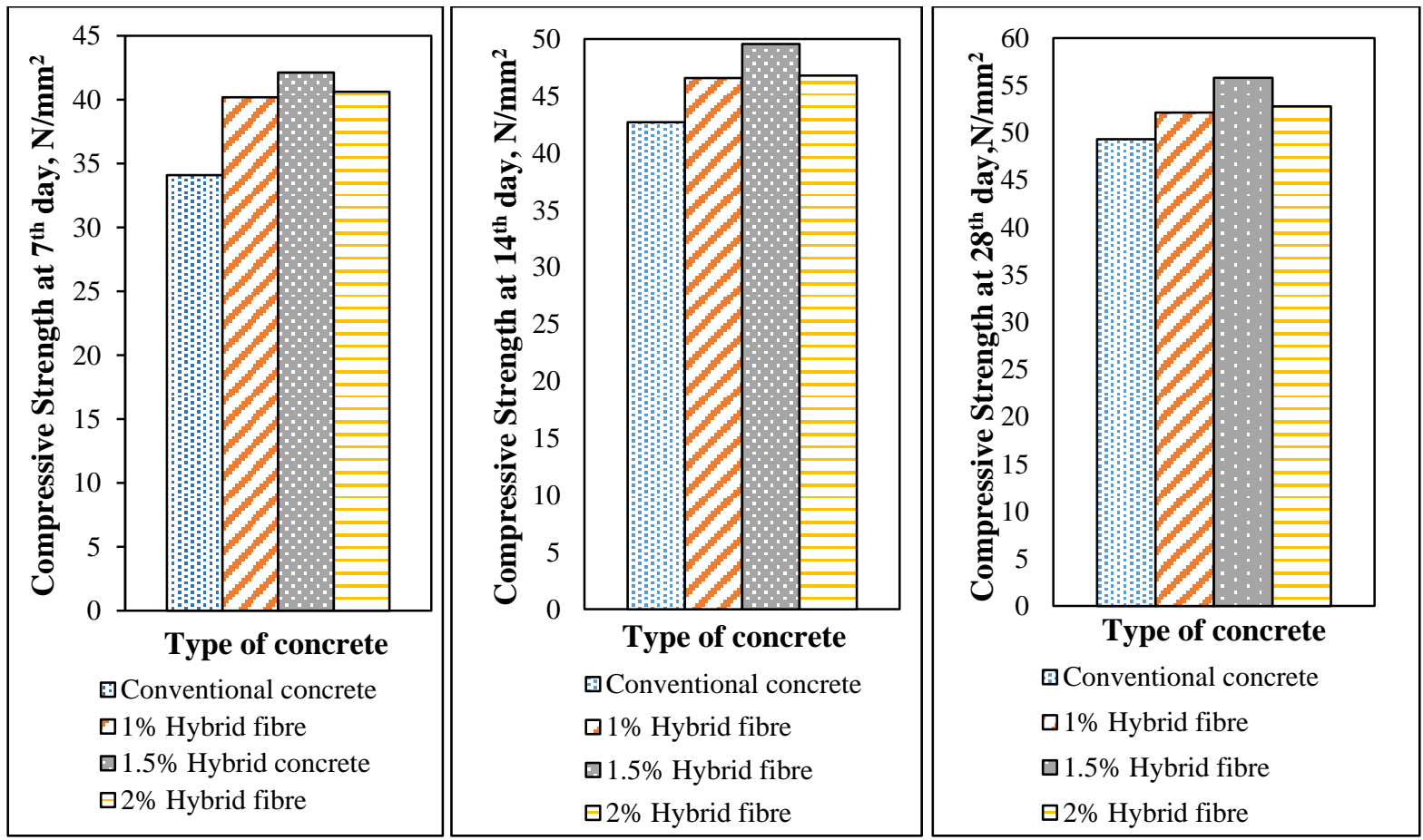

Figure. 2 Compression test results in $\mathrm{N} / \mathrm{mm}^{2}-7^{\text {th }}$ day, $14^{\text {th }}$ day and $28^{\text {th }}$ day. 
The inclusion of the hybrid fibre content increases the compressive strength of the concrete. It is found that as the fibre content increases from 1 to $1.5 \%$ there is an increment in the compressive strength of cubes. Beyond the addition of $1.5 \%$ of fiber content, in the concrete, there is a gradual decrement in the compressive strength of HFRC. The Comparisons of Compressive strength of Conventional to Hybrid concrete at 7, 14 and 28 days of curing were depicted in Fig \#1 revealed that at the age of 7 days the maximum compressive strength attained at $1.5 \%$ addition of hybrid fibers compared to conventional concrete and its counterparts of $1 \%$ and $2 \%$ of fibre inclusion. The same strength attainment observed in the $14^{\text {th }}$ day the maximum compressive strength attained at $1.5 \%$ addition of hybrid fibers continued to increase compared to conventional concrete and its counterparts of $1 \%$ and $2 \%$ of fibre inclusion and as well at the age of 28 days. The $1.5 \%$ hybridization of fibre content dosage in the concrete increased the compressive strength by $13.13 \%$ when compared to the conventional concrete at 28 days. While, the $2 \%$ hybridization of fibre content dosage in the concrete increased the compressive strength only by $7.03 \%$, which is lesser value than $1.5 \%$ hybridization. The percentage of strength increment were depicted in table 8.

Table 8. Compressive strength increment in percentage.

\begin{tabular}{|c|c|c|c|}
\hline Test at & Hybridization at & Hybridization at & Hybridization at \\
intervals & $\mathbf{1 \%}$ & $\mathbf{1 . 5 \%}$ & $\mathbf{2 \%}$ \\
\hline 7 Days & $17.85 \%$ & $23.40 \%$ & $19.12 \%$ \\
\hline 14 Days & $9.11 \%$ & $16.06 \%$ & $9.60 \%$ \\
\hline 28 Days & $5.61 \%$ & $13.13 \%$ & $7.03 \%$ \\
\hline
\end{tabular}




\subsection{Effect of hybrid fibers on splitting tensile strength}

The concrete cylinders made with different hybridization percentages with different testing schedules tested confirming the ASTM C 496:1996 standard. The results were plotted in the graph and depicted in Figure 3.
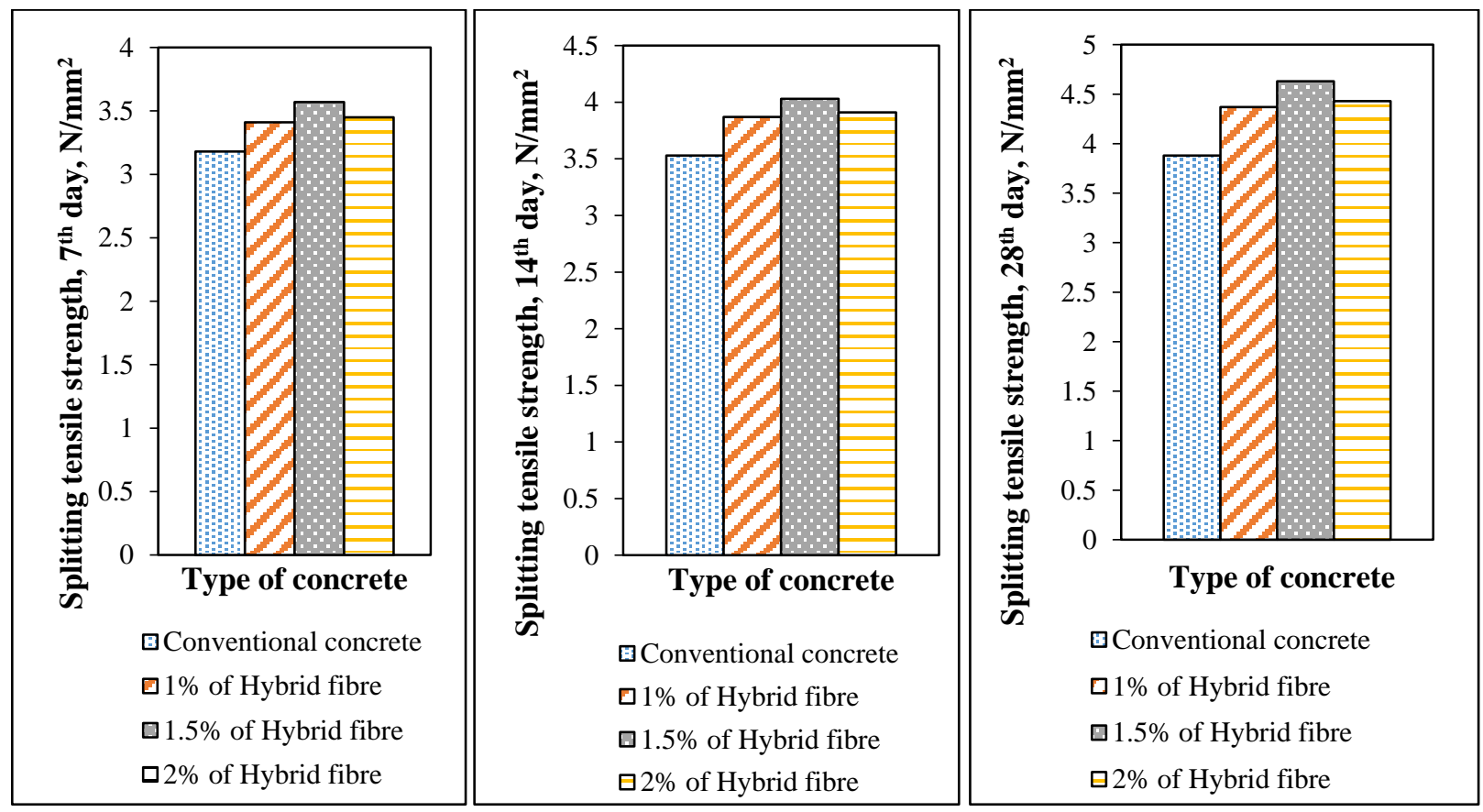

Figure. 3 Splitting tensile test result in $\mathrm{N} / \mathrm{mm}^{2}$ at 7 days, 14 days and 28 days

The inclusion of the hybrid fibre content discretely in the concrete increases the splitting tensile strength. It is found that as the fibre content increases from 1 to $1.5 \%$ there is an increment in the splitting tensile strength of cylinders. Beyond the addition of $1.5 \%$ of fiber content to $2 \%$, there is a gradual decrement in split-tensile strength of HFRC. The Comparisons of split-tensile strength of Conventional to Hybrid concrete at 7, 14 and 28 days of curing were depicted in Figure 3. At $7^{\text {th }}$ day, the maximum splitting tensile strength attained in $1.5 \%$ addition of hybrid 
fibers is higher compared to conventional concrete and its counterparts of $1 \%$ and $2 \%$ of fibre inclusion. The same strength attainment observed in the $14^{\text {th }}$ day the maximum splitting tensile strength attained at $1.5 \%$ addition of hybrid fibers continued to increase compared to conventional concrete and its counterparts of $1 \%$ and $2 \%$ of fibre inclusion and as well at $28^{\text {th }}$ day. The $1.5 \%$ hybridization of fibre content dosage in the concrete increased the splitting tensile strength by $19.33 \%$ when compared to the conventional concrete at 28 days. While, the $2 \%$ hybridization of fibre content dosage in the concrete increased the compressive strength only by $14.17 \%$, which is lesser value than $1.5 \%$ hybridization. The percentage of split-tensile strength increment were depicted in table 9.

Table 9. Percentage of splitting tensile strength increment compared to conventional concrete

\begin{tabular}{|c|c|c|c|}
\hline $\begin{array}{c}\text { Test at } \\
\text { intervals }\end{array}$ & $\mathbf{1 \%} \%$ & $\mathbf{1 . 5 \%}$ & $\mathbf{2 \%}$ \\
\hline 7 Days & $7.23 \%$ & $12.26 \%$ & $8.49 \%$ \\
\hline 14 Days & $9.63 \%$ & $14.16 \%$ & $10.76 \%$ \\
\hline 28 Days & $12.62 \%$ & $19.33 \%$ & $14.17 \%$ \\
\hline
\end{tabular}

\subsection{Effect of hybrid fibers on flexural strength}

The graph in Figure. 4 revealed that as the fibre content increases from 1 to $1.5 \%$ there is an increment in the Flexural tensile strength. Beyond the hybridization of $1.5 \%$ to $2 \%$, there is a gradual decrement in the Flexural tensile strength of HFRC. The percentage of flexural tensile strength peak increment was $25.60 \%$ when the inclusion of Hybrid fibres at $1.5 \%$ compared to the conventional concrete. 


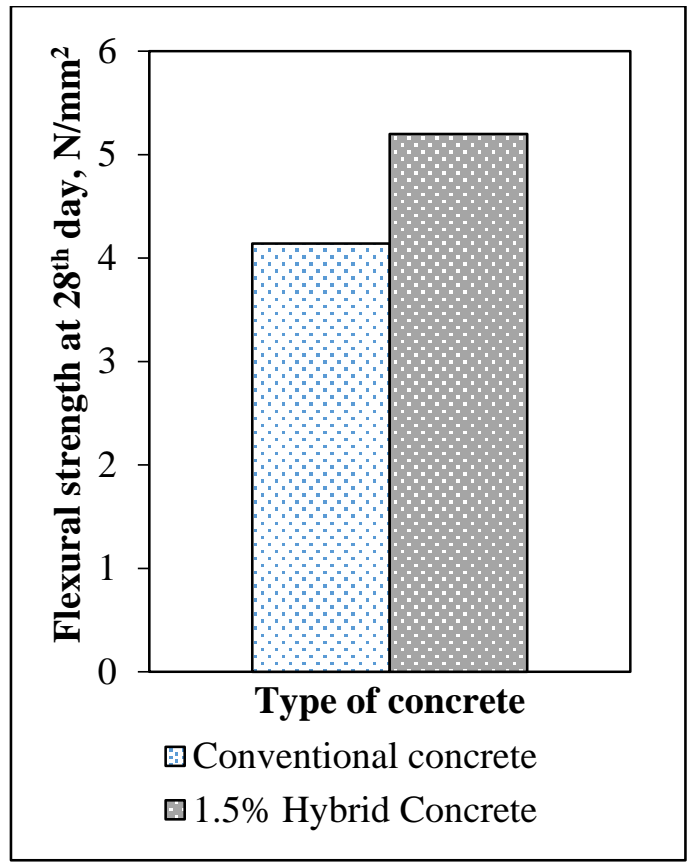

Figure. 4 Flexural strength result in $\mathrm{N} / \mathrm{mm}^{2}$ at 28 days

\section{CONCLUSION}

The experimental work was conducted to study the behaviour of the hybrid fibre added concrete and compare it to the conventional concrete by testing the compression, splitting tensile and the flexural strength. The following conclusions are made based on the result obtained.

- Inclusion of Hybrid-fibres in the conventional concrete increases the ultimate load resistance, tensile strength and delays the post-cracking failure in the flexural test.

- The hybridization of $1.5 \%$ of Steel and polypropylene fibres (50:50) increased the compressive, tensile and flexural strength compared to the conventional concrete and the other two hybridization percentage of $1 \%$ and $2 \%$.

- The compressive strength achieved at $1.5 \%$ of hybridization is $55.8 \mathrm{~N} / \mathrm{mm}^{2}$ which is $13.13 \%$ higher compared to the conventional concrete. 
- The highest tensile strength achieved at $1.5 \%$ addition of hybrid fibers is $4.63 \mathrm{~N} / \mathrm{mm}^{2}$ which is $19.33 \%$ higher compared to conventional concrete.

- The hybridization of $1.5 \%$ to the conventional concrete mix improved the flexural strength from $4.14 \mathrm{~N} / \mathrm{mm}^{2}$ to $5.20 \mathrm{~N} / \mathrm{mm}^{2}$, which is $25.60 \%$ higher strength value.

- The fibre dosage beyond $1.5 \%$ of hybridization was not increased the strength properties of the concrete due to an increase in high fibre content that leads to strength decrement.

- Among the hybridization of $1 \%, 1.5 \%$ and $2 \%$ fibre dosage into the concrete, the $1.5 \%$ was found to be the optimal percentage, which increases the mechanical strength properties when compared to the $1 \%$ and $2 \%$.

\section{REFERENCES}

Bentur \& S. Mindess. 1990. Fibre Reinforced Cementitious Composites. Elsevier Applied Science, London, UK.

Antonio Caggiano a, Serena Gambarelli b, Enzo Martinelli c, Nicola Nisticò b, \& Marco Pepe c. 2016. Experimental characterization of the post-cracking response in Hybrid Steel/Polypropylene Fiber-Reinforced Concrete. Construction and Building Materials, pp 10351043.

C.X. Qiana, \& P. Stroevenb. 2000. Development of hybrid polypropylene-steel fibre-reinforced concrete. Cement and Concrete Research, 30:63-69.

M. Hemapriya, T.P.Meikandaan \& A. Arokiaprakash. 2019. Reinforcement of Hybrid Fibre Reinforced Concrete Beam Using Steel and Polypropylene Fibre. International Journal of Innovative Technology and Exploring Engineering, 8:1016-1019 
Fangqian Denga, Xiaoxiao Dingb, Yin Chia, Lihua Xu, \& Li Wanga. 2018. The pull-out behavior of straight and hooked-end steel fiber from hybrid fiber reinforced cementitious composite: experimental study and analytical modelling. Composite Structures, 206:693-712 N. Banthia \& R. Gupta. 2004. Hybrid fiber reinforced concrete (HyFRC): fiber synergy in high strength matrices. Materials and Structures, 37(10):707-716

Pliya, A-L. Beaucour, \& A. Noumowé. 2011. Contribution of cocktail of polypropylene and steel fibres in improving the behaviour of high strength concrete subjected to high temperature. Construction and Building Materials, 25:1926-1934.

P.S. Song a, J.C. Wu b, S. Hwang c \& B.C. Sheu c. 2005. Statistical analysis of impact strength and strength reliability of steel-polypropylene hybrid fiber-reinforced concrete. Construction and Building Materials, 19:1-9.

S.P. Singh, A.P. Singh \& V. Bajaj. 2010. Strength and flexural toughness of concrete reinforced with steel - polypropylene hybrid fibres. Asian journal of civil engineering (building and housing), 11(4):495-507.

Santhakumar, AR. 2005. Concrete Technology. Oxford press, New Delhi.

Soon Poh Yap, Chun Hooi Bu, U. Johnson Alengaram, Kim Hung Mo \& Mohd Zamin Jumaat. 2014. Flexural toughness characteristics of steel-polypropylene hybrid fibre reinforced oil palm shell concrete. Materials and Design, 57: 652-659 